\title{
BMJ Open Impact of gender on event rates at 1 year in patients with newly diagnosed non-valvular atrial fibrillation: contemporary perspective from the GARFIELD-AF registry
}

\author{
A John Camm, ${ }^{1}$ Gabriele Accetta, ${ }^{2}$ Wael Al Mahmeed, ${ }^{3}$ Giuseppe Ambrosio, ${ }^{4}$ \\ Samuel Z Goldhaber, ${ }^{5}$ Sylvia Haas, ${ }^{6}$ Petr Jansky, ${ }^{7}$ Gloria Kayani, ${ }^{2}$ \\ Frank Misselwitz, ${ }^{8}$ Seil Oh, ${ }^{9}$ Ali Oto, ${ }^{10}$ Pekka Raatikainen, ${ }^{11}$ Jan Steffel, ${ }^{12}$ \\ Martin van Eickels, ${ }^{8}$ Ajay K Kakkar, ${ }^{2,13}$ for the GARFIELD-AF Investigators
}

To cite: Camm AJ, Accetta G, Al Mahmeed W, et al. Impact of gender on event rates at 1 year in patients with newly diagnosed non-valvular atrial fibrillation: contemporary perspective from the GARFIELD-AF registry. BMJ Open 2017;7:e014579. doi:10.1136/bmjopen-2016014579

- Prepublication history and additional material is available. To view please visit the journal (http://dx.doi.org/ 10.1136/bmjopen-2016014579).

Received 4 October 2016 Revised 2 February 2017 Accepted 8 February 2017

CrossMark

For numbered affiliations see end of article.

Correspondence to Professor A John Camm; jcamm@sgul.ac.uk

\section{ABSTRACT}

Objectives: Global Anticoagulant Registry in the FIELD-Atrial Fibrillation (GARFIELD-AF) explored the impact of gender, risk factors and anticoagulant (AC) treatment on 1-year outcomes in patients with nonvalvular atrial fibrillation (NVAF).

Design: GARFIELD-AF is a prospective noninterventional registry.

Setting: Investigator sites $(n=1048)$ are representative of the care settings/locations in each of the 35 countries.

Participants: Patients $\geq 18 y r s$ with newly diagnosed ( $\leq 6$ weeks' duration) NVAF and $\geq 1$ investigatordetermined stroke risk factors.

Main outcome measures: Event rates per 100 person-years were estimated from the Poisson model and HRs and $95 \%$ Cls calculated.

Results: Of 28624 patients (women 44.4\%; men $55.6 \%$ ) enrolled, there were more elderly ( $\geq 75$ years) women $(46.9 \%)$ than men $(30.4 \%)$. All-cause mortality rates per 100 person-years $(95 \% \mathrm{Cl})$ for women and men were 4.48 (4.12 to 4.87) and 4.04 (3.74 to 4.38), respectively, stroke/systemic embolism (SE) (1.62 (1.41 to 1.87$)$ and 1.17 (1.01 to 1.36)) and major bleeding (0.93 (0.78 to 1.13) and 0.79 (0.66 to 0.95)). After adjustment for baseline risk factors in treated and untreated patients, HRs $(95 \% \mathrm{Cl})$ for women (relative to men) for stroke/SE rates were 1.3-fold higher in women (HR 1.30 (1.04 to 1.63)), and similar for major bleeding (1.13 (0.85 to 1.50)) and all-cause mortality (1.05 (0.92 to 1.19)). Antithrombotic treatment patterns in men and women were almost identical. $63.8 \%$ women and $62.9 \%$ men received $\mathrm{AC}_{ \pm}$ antiplatelets. Relative to no $\mathrm{AC}$ treatment, the reduction in stroke/SE rates with $\mathrm{AC}$ treatment was greater $(p=0.01)$ in men (HR $0.45(0.33$ to 0.61$))$ than women $0.77(0.57$ to 1.03$)$. All-cause mortality reduction with AC treatment was similar (women: 0.65 (0.54 to 0.77); men: 0.57 (0.48 to 0.68$)$ ). The risk of major bleeding when treated with $A C$ versus no $A C$ was 2.33 (1.41 to

\section{Strengths and limitations of this study}

Global Anticoagulant Registry in the FIELD-Atrial Fibrillation (GARFIELD-AF) is the largest prospective, ongoing, observational, multicentre, prospective study of patients aged $\geq 18$ years with newly diagnosed NVAF and $\geq 1$ investigatordetermined stroke risk factor(s).

- The GARFIELD-AF registry reflects 'real-world' care settings for unselected patients with nonvalvular AF globally.

- The interpretation of the differences in stroke/ systemic embolism events between men and women is hampered by the lack of data on dosing and persistence with $\mathrm{AC}$ treatment.

$3.84)$ in men and 1.86 (1.16 to 2.99$)$ in women ( $p$ value $=0.53$ ) .

Conclusions: Women have a higher risk of stroke/SE and the reduction in stroke/SE events rates with $A C$ treatment is less in women than in men.

Trial registration number: NCT01090362.

\section{INTRODUCTION}

Every year, $\sim 15$ million people around the world experience a stroke, and 5 million die from their disease. ${ }^{1}$ Ischaemic stroke accounts for the majority of these events, ${ }^{2}$ and patients with atrial fibrillation (AF) are up to five times more likely to experience a stroke than patients without $\mathrm{AF}^{3}{ }^{4}$

Gender differences in the prevalence and prognosis of patients with AF are widely reported (mainly based on epidemiological studies from Europe and North America). ${ }^{5-7}$ 
These studies show that the age-adjusted prevalence of $\mathrm{AF}$ is higher in men than women (596 per 100000 in men and 373 per 100000 in women), ${ }^{5}$ but with greater longevity, women make up the greater proportion $(60 \%)$ of those with $\mathrm{AF}$ who are over the age of 75 years. ${ }^{5} 89$ The prognosis for women with AF markedly differs from men. ${ }^{10}$ Female gender independently increases the risk of stroke, ${ }^{11-16}$ and women with $\mathrm{AF}$ have a higher mortality rate, even after adjustment for baseline comorbid conditions and treatment with anticoagulants (ACs) ${ }^{17}{ }^{18}$ For this reason, female gender is a recognised risk factor for stroke in the $\mathrm{CHA}_{2} \mathrm{DS}_{2}$-VASc stroke risk stratification scheme ${ }^{19}$ as used in international guidelines for stroke prevention in $\mathrm{AF}^{20-23}$ The reason for these disparities in prognosis between men and women are not fully understood.

In this paper, we analysed the impact of gender and gender-associated differences in risk factors and $\mathrm{AC}$ treatment on 1-year outcomes in patients with newly diagnosed non-valvular atrial fibrillation (NVAF) based on data from the Global Anticoagulant Registry in the FIELD-Atrial Fibrillation (GARFIELD-AF) ${ }^{24}$

Previously, we have shown that the use of AC in NVAF does not differ between men and women enrolled in GARFIELD-AF, although many patients received suboptimal thromboprophylaxis, with underuse in moderate-to-high risk patients and overuse in low-risk patients. ${ }^{25}$

\section{MATERIALS AND METHODS}

\section{Study design and patients}

GARFIELD-AF is an ongoing observational, multicentre, prospective study ${ }^{24}$ of patients aged $\geq 18$ years with newly diagnosed ( $\leq 6$ weeks' duration) NVAF and $\geq 1$ investigator-determined stroke risk factor(s). Risk factors are determined by the investigators (a complete list of investigators is given in the online supplementary appendix) and are not prespecified in the protocol, nor are they limited to the components of existing risk stratification schemes. Patients with a transient reversible cause of AF and those for whom follow-up to 2 years is not envisaged or not possible are excluded from the study. Sites were identified globally and on a national level from hospital, community and anticoagulation clinic settings to ensure proportional representation of $\mathrm{AF}$ treating care settings in all countries (as previously described $\left.^{24}\right)$.

\section{Study ethics}

The central ethics committees and regulatory authorities that provided approval are listed in the online supplementary appendix. The registry is being conducted in accordance with the principles of the Declaration of Helsinki, local regulatory requirements and the International Conference on HarmonisationGood Pharmacoepidemiological and Clinical Practice guidelines. All patients provided written informed consent.

\section{Data collection}

Data collected at enrolment included patient and clinical characteristics, medical history, care setting at diagnosis, type of AF, symptoms and antithrombotic treatment (vitamin $\mathrm{K}$ antagonists (VKAs), factor Xa inhibitors and direct thrombin inhibitors). These data were used to calculate the $\mathrm{CHA}_{2} \mathrm{DS}_{2}$-VASc score (Cardiac failure, Hypertension, Age $\geq 75$ (Doubled), Diabetes, Stroke (Doubled)-Vascular disease, Age 65-74 and Sex category (Female)), $\mathrm{CHADS}_{2}$ and HAS-BLED score (Hypertension, Abnormal renal/liver function, Stroke, Bleeding history or predisposition, Elderly ( $>65$ years), Drugs/alcohol concomitantly); data on labile International Normalized Ratio (INR) was not collected and so was not included in the HAS-BLED. Major bleeding was defined according to International Society on Thrombosis and Haemostasis (ISTH) criteria.

The electronic case report form (eCRF) was designed by Dendrite Clinical Systems (Henley-on-Thames, UK). Oversight of operations and data management are being managed by the sponsor and coordinating centre (Thrombosis Research Institute, London, ${ }^{7} \mathrm{UK}$ ), with support from Quintiles (Durham, NC, USA), The University of Birmingham Department of Primary Care Clinical Sciences (Birmingham, UK), Thrombosis Research Group-Brigham and Women's Hospital (Boston, MA, USA) and AIXIAL (Paris, France). Submitted data are examined for completeness and accuracy by the coordinating centre (Thrombosis Research Institute, London, UK). All quality control measures are undertaken under the guidance of an independent audit committee. Key protocol-driven elements of the audit include: frequent electronic data monitoring; remote site monitoring by clinical research associates including source document verification of $20 \%$ of all cases as per the Monitoring Plan. Outcome events were reported by investigators, after review of patient notes and clinical records, and audited using a combination of remote electronic monitoring and more conventional onsite monitoring. Stroke/ systemic embolism (SE), major bleeding and all-cause mortality rates (per 100 persons-years) occurring during the first year of follow-up are calculated using the number of events and the population at risk at the beginning of the follow-up period. Only the first occurrence of each event was taken into account.

\section{Statistical analysis}

Continuous variables are presented as mean $\pm \mathrm{SD}$, and categorical variables are presented as frequency and percentage. Patients with missing values were not removed from the study (available case analysis). Occurrences of major clinical outcomes are described using the persontime event rate (per 100 person-years) and 95\% CI. We estimated person-year rates using a Poisson model, with 
the number of events as the dependent variable and the $\log$ of time as an offset, that is, a covariate with a known coefficient of 1 .

HRs and 95\% CIs were calculated using a proportional hazards Cox regression model after multiple imputations by the Multiple Imputation by Chained Equations (MICE) algorithm assuming that data are missing at random. HRs were adjusted for: age group, race, smoking, diabetes mellitus, hypertension, previous stroke/systemic embolism, history of bleeding, cardiac failure, vascular disease, moderate-to-severe renal disease, AC treatment and type of AF. The proportional hazards assumption was assessed visually using a plot of the survivor function over time by gender. As the model used to estimate the HRs includes interaction between gender and risk factors, we carried out multiple imputations separately for men and women to allow the associations between risk factors and the clinical outcomes to differ according to gender. The model for multiple imputation included baseline characteristics (age, race, type of AF, history of bleeding, diabetes, hypertension, previous stroke, congestive heart failure, vascular disease, AC treatment and hypercholesterolaemia) and clinical endpoints (indicators of death, stroke/SE, major bleeding). We imputed five complete data sets and compared the distribution of the completed and observed data for baseline characteristics to check for any anomalies. Three models were fitted for each clinical outcome: (1) a model estimating the main effect of gender and risk factors. This model does not include interactions between gender and risk factors. The effect of risk factors on clinical outcome is assumed to be the same for men and women; (2) a model with interactions between gender and each risk factor. Using this model, the effect of each risk factor on clinical outcomes separately for men and women were estimated and (3) a model with significant interactions between gender and risk factors. This model includes only significant interactions tested in model 2. Model 1 is presented in online supplementary figure S1 and as online supplementary data, model 2 is presented in main text of the manuscript, whereas model 3 is presented as online supplementary data. All data analyses were performed at the Thrombosis Research Institute using SAS V.9.4 (SAS Institute, Cary, NC, USA) and Stata Statistical Software: Release 14 (StataCorp, College Station, TX, USA).

\section{Patient involvement}

No patients were involved in setting the research question or the outcome measures, nor were they involved in developing plans for design or implementation of the study. No patients were asked to advice on interpretation or writing up of results. There are no plans to disseminate the results of the research to study participants or the relevant patient community. However, we are now including the Anti-Clot Treatment Scale (ACT) as part of the patient assessment in cohort 5 in order to provide a measure of patient-reported outcomes.
RESULTS

\section{Baseline characteristics}

A total of 28624 patients (women 12709 (44.4\%) and men $15915(55.6 \%)$ ) with newly diagnosed NVAF were enrolled into the GARFIELD-AF registry at 1048 sites in 35 countries between March, 2010 and October, 2014. The data were extracted from the study database on 3rd August, 2015. Baseline characteristics are presented by gender in table 1 . The mean (SD) age of women and men were $72.4 \pm 10.4$ years and $67.6 \pm 11.7$ years, respectively; a greater proportion of women than men $(46.9 \%$ vs $30.4 \%$ ) were 75 years or older.

Lifestyle risk factors measured at baseline showed that more men than women were current or ex-smokers (women $15.9 \%$; men $50.1 \%$ ) or heavy drinkers (women $0.4 \%$; men $4.2 \%$ ), with a greater proportion of women being abstinent (men 39.2\%; women $73.0 \%$ ).

A slightly higher proportion of women compared with men were diagnosed with paroxysmal AF (women $29.1 \%$; men $25.1 \%$ ). Women were slightly more likely to have a history of hypertension or raised blood pressure $\geq 140 / 90 \mathrm{~mm} \mathrm{Hg}$ (women $84.8 \%$; men 79.5\%) (table 1). Vascular disease and history of prior coronary artery bypass graft and heart failure (left ventricular ejection fraction $<40 \%$ ) at the time of diagnosis of NVAF were more common in men.

At baseline, mean HAS-BLED scores were $1.5 \pm 0.9$ and $1.4 \pm 0.9$, mean $( \pm \mathrm{SD}) \mathrm{CHADS}_{2}$ scores were 2.0 \pm 1.1 and 1.8 \pm 1.1 and mean $\mathrm{CHA}_{2} \mathrm{DS}_{2}$-VASc scores were $4.0 \pm 1.4$ and 2.6 \pm 1.5 for women and men, respectively. Overall, $97.0 \%$ of women and $76.5 \%$ of men had a $\mathrm{CHA}_{2} \mathrm{DS}_{2}$-VASc score $\geq 2$.

\section{Treatment patterns}

The pattern of antithrombotic treatment in men and women was almost identical (figure 1). At the time of diagnosis, $63.8 \%$ women and $62.9 \%$ men received $\mathrm{AC}$ with or without antiplatelet (AP) therapy; most patients (women 46.8\%; men $46.0 \%$ ) were prescribed VKAswith or without AP treatment, and the remainder (women $17.1 \%$; men $16.9 \%$ ) received non-VKA oral AC (NOACs). Approximately one-quarter of patients (women 23.9\%; men 24.9\%) received AP treatment only. The proportion of women and men who received neither AC treatment nor AP treatment was $12.3 \%$ and $12.2 \%$, respectively. Of patients with a low risk of stroke, $39.7 \%$ of women $\left(\mathrm{CHA}_{2} \mathrm{DS}_{2}\right.$-VASc score $\left.=1\right)$ and $43.3 \%$ of men $\left(\mathrm{CHA}_{2} \mathrm{DS}_{2}-\mathrm{VASc}\right.$ score $\left.=0\right)$ received $\mathrm{AC}$ treatment. Of patients with a high risk of stroke $\left(\mathrm{CHA}_{2} \mathrm{DS}_{2}-\mathrm{VASc}\right.$ score $\geq 2$ ), $35.2 \%$ of women and $33.3 \%$ of men did not receive AC treatment. A minority of women $(n=16)$ used hormone replacement therapy (HRT) (at least two prescriptions at any point prior to a diagnosis of $\mathrm{AF}$ ) and were similarly distributed in the group of anticoagulated $(n=7)$ and non-anticoagulated patients $(n=9)$.

\section{Clinical outcomes over 1 year}

Figure 2 displays unadjusted event rates per 100 personyears and the adjusted HRs for women (with reference 
Table 1 Baseline characteristics of women and men with newly diagnosed atrial fibrillation: the GARFIELD-AF registry

\begin{tabular}{|c|c|c|}
\hline Variable $^{*}$ & Men $(n=15915)$ & Women $(n=12709)$ \\
\hline Age, mean (SD), years & $67.6 \pm 11.7$ & $72.4 \pm 10.4$ \\
\hline \multicolumn{3}{|l|}{ Age group (years), $n(\%)$} \\
\hline$<65$ years & $5847(36.7)$ & $2670(21.0)$ \\
\hline $65-74$ years & 5235 (32.9) & $4082(32.1)$ \\
\hline$\geq 75$ years & $4832(30.4)$ & 5957 (46.9) \\
\hline \multicolumn{3}{|l|}{ Race, n \%† } \\
\hline Caucasian/Hispanic/Latino & $10994(69.1)$ & $9240(72.7)$ \\
\hline Asian & $4228(26.6)$ & $2928(23.0)$ \\
\hline Body mass index, mean (SD), $\mathrm{kg} / \mathrm{m}^{2}$ & $27.7 \pm 5.1$ & $27.9 \pm 6.2$ \\
\hline \multicolumn{3}{|l|}{ LVEF category, $\mathrm{n}(\%)$} \\
\hline$<40 \%$ & $1226(13.1)$ & $4378(6.2)$ \\
\hline$\geq 40 \%$ & 8098 (86.9) & 6609 (93.8) \\
\hline \multicolumn{3}{|l|}{ Type of AF diagnosed, $n(\%)$} \\
\hline Permanent & 2052 (12.9) & $15834(12.5)$ \\
\hline Persistent & 2585 (16.2) & $1782(14.0)$ \\
\hline Paroxysmal & $3988(25.1)$ & $3692(29.1)$ \\
\hline New (unclassified) & $7289(45.8)$ & $5651(44.5)$ \\
\hline \multicolumn{3}{|l|}{ Medical history, $n(\%)$} \\
\hline \multicolumn{3}{|l|}{ Congestive heart failure, NYHA Class, $n(\%)$} \\
\hline 1 & $632(21.2)$ & $416(17.0)$ \\
\hline II & $1408(47.3)$ & $1241(50.7)$ \\
\hline III & $792(26.6)$ & $682(27.8)$ \\
\hline IV & $146(4.9)$ & $111(4.5)$ \\
\hline Carotid occlusive disease, $\mathrm{n}(\%)$ & $505(3.2)$ & $361(2.9)$ \\
\hline PE or DVT, $n(\%)$ & $362(2.3)$ & $403(3.2)$ \\
\hline Systemic embolism & $100(0.6)$ & $94(0.7)$ \\
\hline Coronary artery bypass graft, $\mathrm{n}(\%)$ & $689(4.4)$ & $164(1.3)$ \\
\hline Moderate to severe CKD, $\mathrm{n}(\%)$ & $1458(9.2)$ & $1511(11.9)$ \\
\hline Stroke/TIA, n (\%) & $1839(11.6)$ & $1583(12.5)$ \\
\hline Stroke, n (\%) & $1243(7.8)$ & $1013(8.0)$ \\
\hline History of bleeding, $n(\%)$ & $469(3.0)$ & $311(2.5)$ \\
\hline \multicolumn{3}{|l|}{ Blood pressure, $\mathrm{mm} \mathrm{Hg}$} \\
\hline Systolic blood pressure, mm Hg, mean (SD) & $132.8( \pm 19.3)$ & $135.0( \pm 20.7)$ \\
\hline Diastolic blood pressure, $\mathrm{mm} \mathrm{Hg}$, mean (SD) & $80.1( \pm 12.8)$ & $79.8( \pm 13.0)$ \\
\hline Blood pressure $\geq 140 / 90 \mathrm{~mm} \mathrm{Hg}, \mathrm{n}(\%)$ & $4037(27.2)$ & $3741(31.5)$ \\
\hline History of hypertension, $\mathrm{n}(\%)$ & $11945(75.2)$ & $10212(80.5)$ \\
\hline History of hypertension or raised blood pressure $\geq 140 / 90 \mathrm{~mm} \mathrm{Hg}, \mathrm{n}(\%)$ & $12634(79.5)$ & $10773(84.8)$ \\
\hline Hypercholesterolaemia, n (\%) & $6232(39.9)$ & $5276(42.3)$ \\
\hline Diabetes mellitus, $\mathrm{n}(\%)$ & 3479 (21.9) & $2728(21.5)$ \\
\hline Vascular disease $\neq$, n (\%) & $2820(17.7)$ & 1508 (11.9) \\
\hline \multicolumn{3}{|l|}{ CHA2DS2-VASc score } \\
\hline Mean (SD) & $2.6(1.5)$ & $4.0(1.4)$ \\
\hline $0, \mathrm{n}(\%)$ & $676(4.4)$ & - \\
\hline $1, \mathrm{n}(\%)$ & $2966(19.1)$ & $370(3.0)$ \\
\hline$\geq 2, n(\%)$ & $11857(76.5)$ & $12082(97.0)$ \\
\hline Mean HAS-BLED score (SD) & $1.4(0.9)$ & $1.5(0.9)$ \\
\hline Heavy alcohol consumption, n (\%) & $565(4.2)$ & $40(0.4)$ \\
\hline Current/previous smoker, $\mathrm{n}(\%)$ & $7210(50.1 \%)$ & $1850(15.9 \%)$ \\
\hline
\end{tabular}

${ }^{*}$ Missing patients from analyses: Number of patients (men, women) with missing values: age $(0,0)$, race $(429346)$, body mass index $(3231$, 2858), blood pressure (1051, 830), LVEF (6591, women), type of AF diagnosed (1, 1), congestive heart failure, NYHA class (228, 189), carotid occlusive disease $(117,87)$, PE or DVT $(46,47)$, systemic embolism $(48,43)$, coronary artery bypass graft $(350,208)$, moderate to severe $\operatorname{CKD}(2,1)$, stroke $(33,30)$, history of bleeding $(37,38)$, hypertension $(22,23)$, hypercholesterolaemia $(300,248)$, diabetes mellitus $(1,1)$ vascular disease $(1,1)$, CHA2DS2-VASc score $(416,257)$, HAS-BLED score (5230, 3947), alcohol consumption $(2516,1893)$ smoking habits $(1529,1052)$.

†346 women and 427 men were unwilling to declare their race or their race was not recorded.

$\ddagger$ Peripheral artery disease or coronary artery disease with a history of acute coronary syndromes.

$\mathrm{AF}$, atrial fibrillation; $\mathrm{CKD}$, chronic kidney disease; $\mathrm{CHA}_{2} \mathrm{DS}_{2}$-VASc score, Cardiac failure, Hypertension, Age $\geq 75$ (Doubled), Diabetes, Stroke (Doubled)-Vascular disease, Age 65-74 and Gender category (Female); DVT, deep venous thrombosis; HAS-BLED, Hypertension (uncontrolled, $>160 \mathrm{~mm} \mathrm{Hg}$ systolic), Abnormal renal/liver function, Stroke, Bleeding history or predisposition (anaemia), Elderly (>65) and Drugs/alcohol concomitantly (antiplatelet agents, non-steroidal anti-inflammatory drug); LVEF, left ventricular erection fraction; NYHA, New York Heart Association; PE, Pulmonary embolism; TIA, Transient ischaemic attack. 


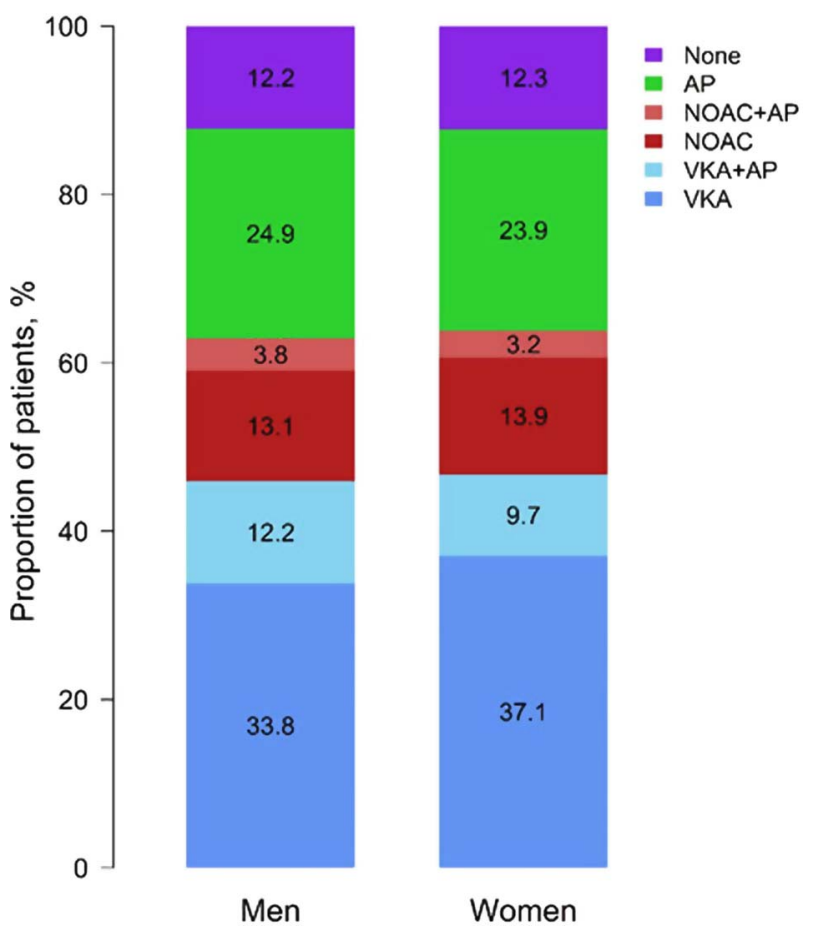

Figure 1 Antithrombotic treatment at diagnosis. AP, antiplatelet; NOAC, non-vitamin $\mathrm{K}$ antagonist oral anticoagulants; VKA, vitamin $\mathrm{K}$ antagonists.
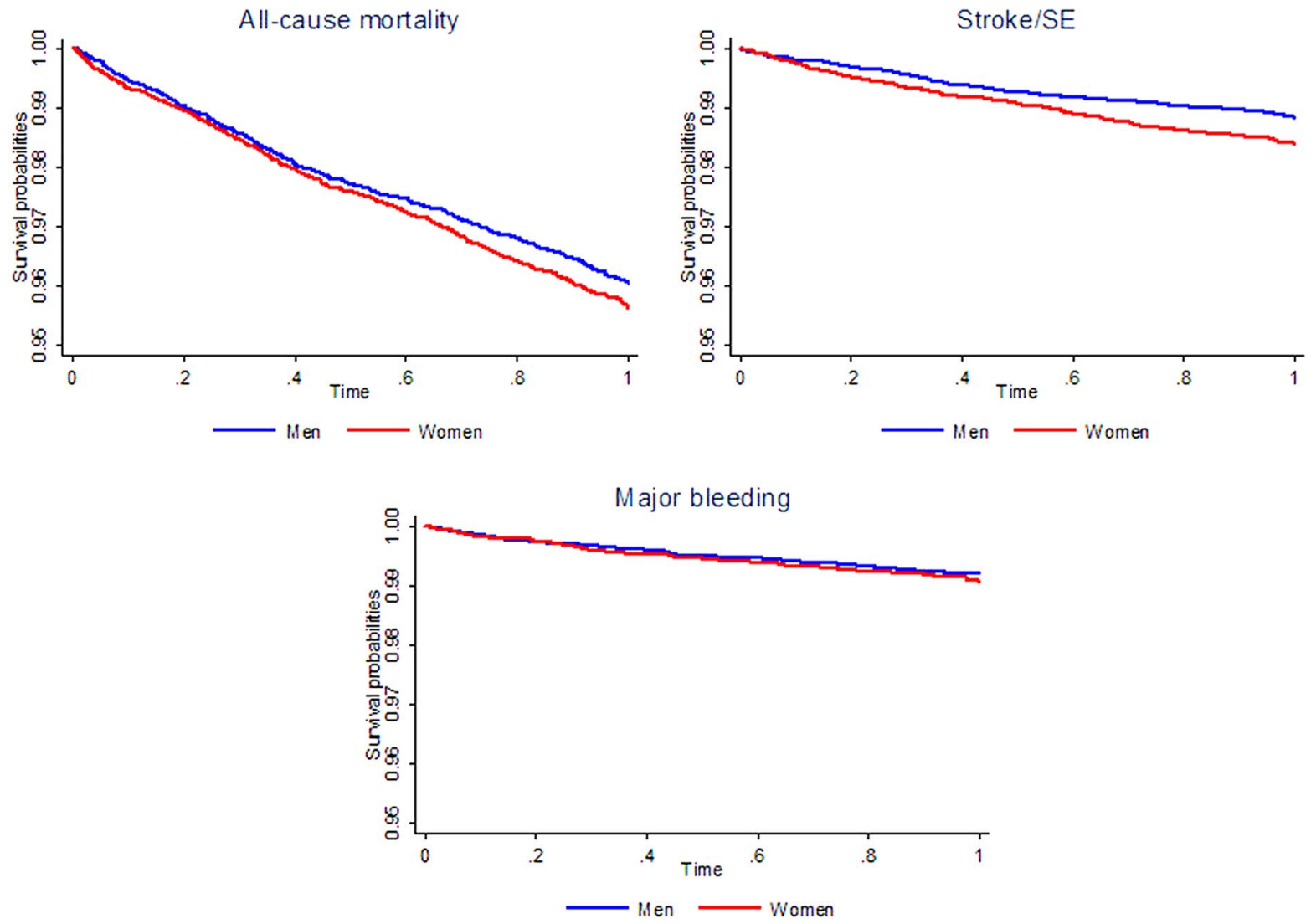

Figure 2 Kaplan-Meir curves for men and women for all-cause mortality, stroke/SE and major bleeding during the first year of follow-up. SE, systemic embolism. to men). Unadjusted event rates per 100 person-years $(95 \% \mathrm{CI})$ in women and men, respectively, were: stroke/SE (1.62 (1.41 to 1.87$)$ and 1.17 (1.01 to 1.36$)$ ), major bleeding (0.93 (0.78 to 1.13 ) and 0.79 (0.66 to 0.95$)$ ) and all-cause mortality (4.48 (4.12 to 4.87$)$ and 4.04 (3.74 to 4.38$)$ ). When HRs (95\% CI) were adjusted for baseline risk factors (as defined in figure 2), stroke/SE were 1.3-fold higher for women compared with men (HR 1.30 (1.04 to 1.63)), whereas the HR for major bleeding was 1.13 (0.85 to 1.50$)$ and for all-cause mortality, the HR was 1.05 (0.92 to 1.19 ).

\section{Multivariate Cox regression analysis of HRs adjusted for risk factors by gender}

Adjusted HRs estimated using model 1 describe the effect of gender on clinical outcomes (figure 2 and online supplementary tables S1-S3). Model 2 with HRs adjusted for risk factors by gender for all clinical outcomes is presented in figure 3 and in table 2. Additional information from the statistical models 1 and 3 and missing values are presented in the appendix (see online supplementary tables S1-S4, respectively). Our results are robust when removing non-significant interactions (model 3), but for descriptive purposes, we present the results from model 2, which includes 24852 
Figure 3 Forest plot of HRs for 1-year clinical outcomes according to risk factors in men and women (Square to men and Circle to women). AC, anticoagulation; $A F$, atrial fibrillation; SE, systemic embolism; TIA, transient ischaemic attack. Adjustment factors for HRs: age group, race, smoking, diabetes mellitus, hypertension, previous stroke/TIA/ systemic embolism, history of bleeding, congestive heart failure (CHF), vascular disease, moderate-to-severe renal disease, anticoagulant treatment and type of atrial fibrillation. Hypertension was defined as a documented history of hypertension or blood pressure $>140 / 90 \mathrm{~mm} \mathrm{Hg}$. Results of Model 2.
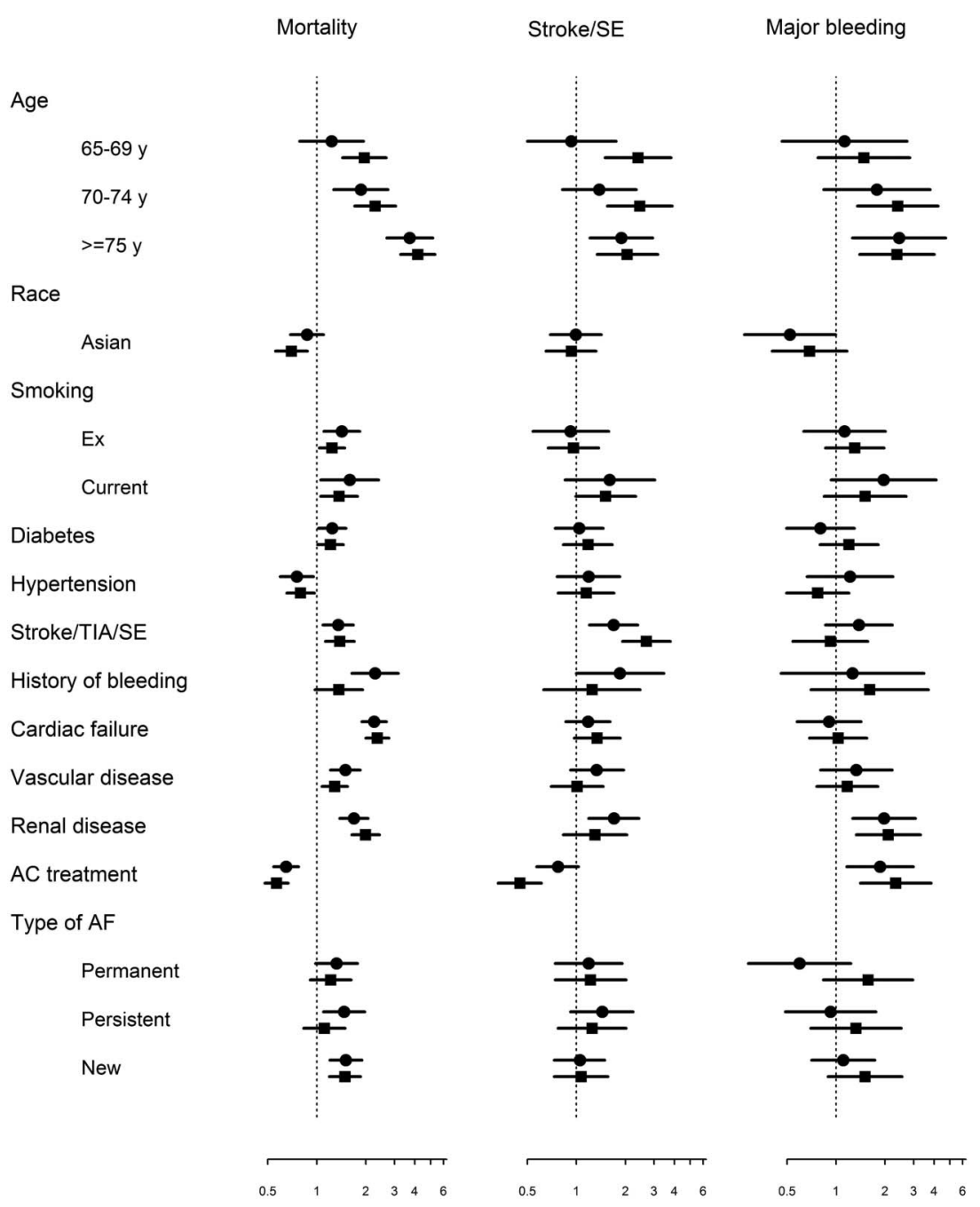

complete cases and 3772 patients with at least one imputed value (table 2 ).

The analyses show that the risk of all clinical endpoints increases with advancing age in men and women. Men from the age of 65 years have an elevated risk of all endpoints compared with younger men with AF ( $<65$ years). In contrast, the stroke risk is elevated in women only from the age of 70 onwards compared with women with AF ( $<65$ years).

Patients with NVAF from Asia have a lower risk of allcause mortality and major bleeding (but not stroke) compared with patients of other ethnicities (Caucasian, Hispanic or Latino); the risk of events is similar across ethnicities of the same gender (figure 3 and table 2).

Current smoking is a risk factor for all events and cessation of smoking was associated with reduced risk of events (relative to current smokers) in both genders. Diabetes mellitus carried a similar risk for all-cause mortality in men and women with NVAF. Hypertension (predominantly characterised by a history of hypertension) was associated with a reduction in the risk of 1-year allcause mortality in men and women and was an equally important risk factor for stroke in men and women. Hypertension was also associated with an increased risk of major bleeding in women, but not men, but this gender difference was not statistically significant (women: HR 1.22 (95\% CI 0.66 to 2.24$)$; men: HR 0.77 $(95 \%$ CI 0.50 to 1.20$) ; \mathrm{p}=0.23$; table 2$)$. An equally important risk factor for all-cause mortality in women and men with AF was congestive heart failure $(\mathrm{HR}>2)$. A history of bleeding was associated with a higher risk of all events, but with a significantly elevated risk of allcause mortality in women compared with men (women: HR 2.28 (95\% CI 1.64 to 3.17$)$, men HR 1.37 (95\% CI 0.98 to 1.91 ) $\mathrm{p}=0.03$; table 2 ).

Severe renal disease was associated in an elevated risk of all events in both genders. The risk of stroke in patients with vascular disease appeared to be elevated in women but not men (women: HR 1.33 (0.92 to 1.95); men: HR 1.01 ( 0.70 to 1.46$)$; although the difference was not statistically significant $\mathrm{p}=0.30$ ) (figure 3 and table 2 ).

In women and men, prior stroke/transient ischaemic attack/SE was a risk factor for a subsequent stroke event and this risk was significantly lower in women than in men (women: 1.69 (1.20 to 2.38 ); men: 2.69 (1.92 to 3.77); $\mathrm{p}=0.06)$.

Compared with no $\mathrm{AC}$ treatment, $\mathrm{AC}$ treatment lowered the risk of stroke/SE to a greater extent in men 
Table 2 Adjusted HRs (95\% Cls) according to risk factors by gender and $\mathrm{p}$ values for the interaction between gender and risk factors

\begin{tabular}{|c|c|c|c|c|c|c|}
\hline \multirow[b]{2}{*}{ Risk factor } & \multicolumn{2}{|l|}{ All-cause mortality } & \multicolumn{2}{|l|}{ Stroke/SE } & \multicolumn{2}{|l|}{ Major bleeding } \\
\hline & Women & Men & Women & Men & Women & Men \\
\hline Age & $\mathrm{p}=0.71$ & & $\mathrm{p}=0.17$ & & $p=0.64$ & \\
\hline $65-69$ years (ref: <65) & 1.23 (0.78 to 2.67$)$ & 1.96 (1.44 to 2.67$)$ & $0.93(0.50$ to 1.75$)$ & 2.39 (1.50 to 3.81$)$ & $1.13(0.47$ to 2.73$)$ & $1.48(0.77$ to 2.84$)$ \\
\hline 70-74 years (ref: $<65$ ) & $1.86(1.27$ to 2.74$)$ & $2.28(1.71$ to 3.05$)$ & $1.38(0.82$ to 2.33$)$ & 2.45 (1.55 to 3.87$)$ & $1.78(0.84$ to 3.78$)$ & $2.39(1.35$ to 4.24$)$ \\
\hline $\begin{array}{l}\geq 75 \text { years (ref: }<65 \text { ) } \\
\text { Race }\end{array}$ & $\begin{array}{l}3.72(2.69 \text { to } 5.15) \\
p=0.33\end{array}$ & 4.17 (3.27 to 5.32$)$ & $\begin{array}{l}1.89(1.21 \text { to } 2.94) \\
p=0.89\end{array}$ & 2.05 (1.34 to 3.16$)$ & $\begin{array}{l}2.44(1.26 \text { to } 4.72) \\
p=0.51\end{array}$ & $2.37(1.40$ to 4.01$)$ \\
\hline Asian (ref: Caucasian/Hispano/Latino) & $0.87(0.69$ to 1.10$)$ & 0.70 (0.56 to 0.88$)$ & $0.99(0.60$ to 1.42$)$ & 0.93 (0.65 to 1.32$)$ & $0.52(0.27$ to 0.99$)$ & $0.69(0.41$ to 1.17$)$ \\
\hline Ex-smoker (ref: no) & $1.42(1.11$ to 1.84$)$ & 1.24 (1.04 to 1.48$)$ & $0.92(0.54$ to 1.58$)$ & 0.96 (0.67 to 1.37$)$ & $1.13(0.63$ to 2.01$)$ & $1.30(0.86$ to 1.97$)$ \\
\hline Current smoker (ref: no) & $1.59(1.06$ to 2.40$)$ & $1.37(1.06$ to 1.78$)$ & $1.60(0.85$ to 3.03$)$ & $1.51(0.99$ to 2.31$)$ & $1.96(0.93$ to 4.12$)$ & 1.55 (0.84 to 2.70$)$ \\
\hline Diabetes mellitus & $\mathrm{p}=0.86$ & & $\mathrm{p}=0.63$ & & $\mathrm{p}=0.21$ & \\
\hline Yes (ref: no) & $1.24(1.02$ to 1.51$)$ & 1.21 (1.01 to 1.46$)$ & $1.04(0.74$ to 1.46$)$ & 1.18 (0.83 to 1.66$)$ & $0.80(0.50$ to 1.30$)$ & $1.20(0.80$ to 1.81$)$ \\
\hline Hypertension & $\mathrm{p}=0.73$ & & $\mathrm{p}=0.90$ & & $\mathrm{p}=0.23$ & \\
\hline Yes (ref: no) & 0.75 (0.60 to 0.95$)$ & 0.79 (0.65 to 0.97$)$ & $1.19(0.76$ to 1.85$)$ & $1.15(0.77$ to 1.70$)$ & $1.22(0.66$ to 2.24$)$ & $0.77(0.50$ to 1.20$)$ \\
\hline Stroke/TIA/SE & $\mathrm{p}=0.88$ & & $\mathrm{p}=0.06$ & & $\mathrm{p}=0.27$ & \\
\hline Yes (ref: no) & 1.35 (1.09 to 1.68$)$ & $1.38(1.13$ to 1.70$)$ & $1.69(1.20$ to 2.38$)$ & 2.69 (1.92 to 3.77$)$ & 1.38 (0.86 to 2.22$)$ & $0.92(0.54$ to 1.57$)$ \\
\hline History of bleeding & $\mathrm{p}=0.03$ & & $\mathrm{p}=0.40$ & & $\mathrm{p}=0.72$ & \\
\hline Yes (ref: no) & 2.28 (1.64 to 3.17$)$ & 1.37 (0.98 to 1.91$)$ & $1.85(1.00$ to 3.44$)$ & 1.25 (0.63 to 2.46$)$ & $1.26(0.46$ to 3.47$)$ & $1.61(0.70$ to 3.69$)$ \\
\hline Congestive heart failure & $\mathrm{p}=0.72$ & & $\mathrm{p}=0.57$ & & $\mathrm{p}=0.68$ & \\
\hline Yes (ref: no) & 2.25 (1.89 to 2.68$)$ & 2.35 (2.00 to 2.77 ) & $1.18(0.86$ to 1.61$)$ & 1.34 (0.97 to 1.86$)$ & 0.91 (0.58 to 1.42$)$ & $1.03(0.69$ to 1.55$)$ \\
\hline Vascular disease & $\mathrm{p}=0.29$ & & $\mathrm{p}=0.30$ & & $\mathrm{p}=0.70$ & \\
\hline Yes (ref: no) & $1.50(1.21$ to 1.85$)$ & 1.29 (1.08 to 1.55$)$ & $1.33(0.92$ to 1.95$)$ & $1.01(0.70$ to 1.46$)$ & $1.33(0.80$ to 2.21$)$ & $1.17(0.76$ to 1.80$)$ \\
\hline Severe renal disease & $\mathrm{p}=0.25$ & & $\mathrm{p}=0.36$ & & $\mathrm{p}=0.85$ & \\
\hline grade III-IV-V (ref: I, II, no, unknown) & 1.69 (1.38 to 2.07$)$ & 1.99 (1.64 to 2.42$)$ & 1.70 (1.19 to 2.42$)$ & 1.30 (0.83 to 2.04$)$ & 1.97 (1.27 to 3.07$)$ & $2.10(1.33$ to 3.30$)$ \\
\hline AC treatment & $\mathrm{p}=0.28$ & & $\mathrm{p}=0.01$ & & $\mathrm{p}=0.53$ & \\
\hline Yes (ref: no) & 0.65 (0.54 to 0.77$)$ & $0.57(0.48$ to 0.67$)$ & 0.77 (0.57 to 1.03$)$ & $0.45(0.33$ to 0.61$)$ & $1.86(1.16$ to 2.99$)$ & $2.33(1.41$ to 3.84$)$ \\
\hline Type of AF & $\mathrm{p}=0.49$ & & $\mathrm{p}=0.96$ & & $\mathrm{p}=0.27$ & \\
\hline Permanent AF (ref: no) & $1.32(0.98$ to 1.78$)$ & $1.22(0.91$ to 1.62$)$ & $1.19(0.74$ to 1.91$)$ & $1.22(0.74$ to 2.02$)$ & $0.60(0.29$ to 1.23$)$ & $1.57(0.84$ to 2.96$)$ \\
\hline Persistent AF (ref: no) & $1.47(1.10$ to 1.97$)$ & $1.11(0.83$ to 1.49$)$ & $1.44(0.92$ to 2.23$)$ & 1.25 (0.77 to 2.02$)$ & $0.93(0.49$ to 1.76$)$ & $1.33(0.70$ to 2.51$)$ \\
\hline New AF (ref: no) & $1.51(1.20$ to 1.89$)$ & $1.49(1.20$ to 1.86$)$ & $1.05(0.73$ to 1.49$)$ & $1.07(0.73$ to 1.56$)$ & $1.11(0.71$ to 1.73$)$ & $1.51(0.89$ to 2.54$)$ \\
\hline
\end{tabular}


than women (women: HR 0.77 (95\% CI 0.57 to 1.03 ); men: HR 0.45 (95\% CI 0.33 to 0.61$)$ ), and this interaction was significant $(\mathrm{p}=0.01)$. The reduction in allcause mortality with AC treatment was similar in both genders (women: HR 0.65 (95\% CI 0.54 to 0.77 ); men: HR 0.57 (95\% CI 0.48 to 0.68 )). Men, however, had a higher risk of major bleeding when treated with ACs (HR 2.33 (95\% CI 1.41 to 3.84)) compared with women (HR 1.86 (95\% CI 1.16 to 2.99)); although this interaction was not significant.

\section{DISCUSSION}

The GARFIELD-AF study found that women had a higher risk of stroke/SE than men even after adjustment of risk factors (congestive heart failure, age, hypertension, diabetes mellitus, prior stroke/SE, vascular disease and history of bleeding). The event rates from GARFIELD-AF correspond to the results from two recent meta-analyses of pooled data from the literature which determined that the unadjusted risk of stroke in women, relative to men, was 1.47 (95\% CI 1.18 to 1.83$)^{26}$ and the adjusted risk was 1.31 (1.18 to 1.46$){ }^{27}$

The impact of gender on all-cause mortality in patients with $\mathrm{AF}$ is inconsistently reported in the literature. ${ }^{26}$ The results from the GARFIELD-AF study of $>28000$ patients found that the unadjusted rate of allcause mortality per 100 person-years was only slightly elevated in women (4.48) compared with men (4.04). After adjustment for baseline risk factors, all-cause mortality in women, relative to men, was similar.

Our analysis highlights differences in patient characteristics between men and women presenting with NVAF. One of the most notable differences is age. At the time of enrolment in the GARFIELD-AF registry, the mean age of patients with newly diagnosed NVAF was lower for men than women (68 vs 72 years). This result is comparable with age distribution between women and men which has been reported in other studies of patients with AF such as the Monitoring and Observing the Value of Exercise (MOVE) study (67 vs 71 years), ${ }^{28}$ RAte Control versus Electrical cardioversion for persistent atrial fibrillation (RACE) (67 vs 71 years) ${ }^{29}$ and the Euro Heart Survey (ESC) (64 vs 70 years). ${ }^{30}$

Of note, there was a greater proportion of women than men who were 75 years or older at the time of diagnosis of NVAF which is in accordance with other studies. $^{8} 31$ There was also a trend toward a greater prevalence of comorbid vascular disease in men (than women) and comorbid hypertension in women. Otherwise, the prevalence of other risk factors for stroke (diabetes, prior stroke/SE) is similar in men and women. The Framingham study found that gender differences in blood pressure gradually narrow with age. Eventually, women develop higher blood pressure than men (beyond age 60 years) with the accelerated onset of arterial stiffening beyond menopause (especially in women with a history of hypertension).$^{32}$
As reflected in the mean $\mathrm{CHA}_{2} \mathrm{DS}_{2}$-VASc scores $(4.0 \pm 1.4$ and 2.6 \pm 1.5 for women and men) beyond the impact of gender, there are only small differences in the risk factors for stroke in men and women with newly diagnosed NVAF. This difference can be explained by the greater age of female patients. ${ }^{33}$ In GARFIELD-AF, we found that only prior stroke and AC treatment were significantly associated with gender-related differences in stroke event rates after adjustment for baseline risk factors.

It is recognised that the risk of thromboembolism increases with advancing age in patients above 65 years. ${ }^{34}$ Similar to the Danish registry, which calculated stroke rates according to sex and age, we found that the risk of stroke tended to be elevated in women only from the age of 70 years and in men from 65 years onwards compared with patients of the same gender with $\mathrm{AF}$ ( $<65$ years). However, the Loire Valley AF study reported that in relatively young patients with $\mathrm{AF}$ ( $<65$ years), the risk of stroke/thromboembolism can be independently increased by the presence of heart failure, prior stroke or vascular disease. ${ }^{31}$ In GARFIELD-AF, even though men were younger than women at the time of AF diagnosis (mean age for men: 67.6 years), they were more likely to present with vascular disease, be current/past smokers (and/or heavy drinkers) and as likely to have had a history of heart failure (New York Heart Association (NYHA) class III-IV) or prior stroke/transient ischaemic attack as older women. We found that there was an unexpectedly higher risk of recurrent stroke in men than in women in the year following the diagnosis of $\mathrm{AF}$.

The effects of AC treatment on stroke prevention were significantly greater in men than in women but were also associated with greater risk of bleeding. We found that the pattern of AC treatment did not differ markedly in men and women or among the minority of women $(n=19)$ who had received HRT. Nevertheless, subtle differences in prescribing patterns by gender are evident. For example, AC treatment in combination with AP therapy was more frequently prescribed for men than women, which may have contributed to the increased risk of bleeding with $\mathrm{AC}$ treatment in men. Other published studies have shown that gender and age also influence dose. For example, women require less warfarin to maintain a therapeutic INR than men at an equivalent age and dosing reduces proportionally with increasing age. ${ }^{35}$ The greater risk of bleeding in men may be explained by more aggressive AC dosing in men (relative to women). Conversely, the lower impact of AC treatment on stroke rates in women may be due to poorer anticoagulation control as determined by Atrial Fibrillation Follow-up Investigation of Rhythm Management (AFFIRM). ${ }^{36}$ In this study, women were more likely to be outside the time in therapeutic range (TTR) and have subtherapeutic INRs. However, the GARFIELD-AF showed that the mean (SD) TTR is similar in men, 55.6 (27.1) and women, 55.2 (26.9).

An important consideration in women is the impact of age on prescribing practice and adherence to 
medication, since a higher proportion of women than men were elderly ( 75 years or older). There is also evidence (from a recent meta-analysis of randomised controlled studies reporting annualised event rates) that women with $\mathrm{AF}$ have a significantly greater residual risk of stroke/SE (compared with men) when treated using warfarin. The AFFIRM study, for example, showed that women who had a comparably high TTR $(>66 \%)$ still had significantly more ischaemic strokes. ${ }^{36}$ However, this gender difference is not observed in randomised controlled trials (RCTs) with NOACs. ${ }^{15}$ The same meta-analysis of RCTs also found that NOAC agents are associated with significantly more major bleeding in men than women. The reason for these gender differences in controlled clinical trials is not completely understood. ${ }^{15}$

\section{CONCLUSIONS}

Across the models, we found that only prior stroke and $\mathrm{AC}$ treatment were significantly associated with genderrelated differences in stroke event rates after adjustment for baseline risk factors. The increased benefit of AC treatment on stroke prevention in men, relative to women, is not fully understood, but suggests that women may be less well anticoagulated.

\author{
Author affiliations \\ ${ }^{1}$ St George's University of London, and Imperial College, London, UK \\ ${ }^{2}$ Thrombosis Research Institute, London, UK \\ ${ }^{3}$ Heart and Vascular Institute, Cleveland Clinic, Abu Dhabi, United Arab \\ Emirates \\ ${ }^{4}$ University of Perugia School of Medicine, Perugia, Italy \\ ${ }^{5}$ Harvard Medical School, Boston, USA \\ ${ }^{6}$ Formerly Technical University of Munich, Munich, Germany \\ ${ }^{7}$ Motol University Hospital, Prague, Czech Republic \\ ${ }^{8}$ Bayer HealthCare Pharmaceuticals, Berlin, Germany \\ ${ }^{9}$ Seoul National University College of Medicine, Seoul, Republic of Korea \\ ${ }^{10}$ Hacettepe University, Ankara, Turkey \\ ${ }^{11}$ Tampere University Hospital, Tampere, Finland \\ ${ }^{12}$ University Hospital Zurich, Zurich, Switzerland \\ ${ }^{13}$ University College London, London, UK
}

Acknowledgements The authors would like to acknowledge the support of the following people in the preparation of this manuscript: Keith A.A. Fox and Bernhard J. Gersh for their supervisory role in the audit of GARFIELD-AF data; David Hofman (TRI, London), UK for SAS programming support; Rae Hobbs (TRI, London, UK) and Christina Johnsen (TRI, London, UK) for medical writing support and Surekha Damineni (TRI, London, UK) for editorial support.

Collaborators JC, Professor, Cardiology Clinical Academic Group, St George's University of London and Imperial College, London, UK; GA, Lead Statistician, Thrombosis Research Institute, London, UK; WAM, Consultant Cardiologist, Heart and Vascular Institute, Cleveland Clinic, Abu Dhabi, United Arab Emirates; GA, Professor, University of Perugia School of Medicine, Perugia, Italy; SZG, Professor, Harvard Medical School, Boston, USA; SH, Emeritus Professor of Medicine, Formerly Technical University of Munich, Munich, Germany; PJ, Head of Internal Medicine, Motol University Hospital, Prague, Czech Republic; GK, Chief Operating Officer, Thrombosis Research Institute, London, UK; FM, Corporate Vice President, Bayer HealthCare Pharmaceuticals, Berlin, Germany; So, Professor Seoul National University College of Medicine, Seoul, Republic of Korea; A0, Professor, Hacettepe University, Ankara, Turkey; PR, Professor, Tampere University Hospital, Tampere, Finland; JS, CoHead Invasive Electrophysiology and Devices Leitender Arzt Cardiology, University Hospital Zurich, Zurich, Switzerland; MvE, Director Global Medical Affairs, Bayer HealthCare Pharmaceuticals,
Berlin, Germany; AKK, Director, Thrombosis Research Institute and Professor, University College London, London, UK.

Contributors AJC, WAM, GA, SZG, PJ, GK, FM, SO, AO, PR, JS, MvE and AKK contributed to the study design. AJC, WAM, GA, SZG, PJ, SO, AO, PR and JS contributed to data acquisition. GA analysed the data. All authors contributed to data interpretation. AJC drafted the report. All authors critically reviewed the report and approved the final manuscript.

Funding The GARFIELD-AF registry is sponsored by the TRI, London, UK, and is supported by an unrestricted research grant from Bayer AG, Berlin, Germany (AKK).

Disclaimer The funding source had no involvement in the data collection, data analysis or data interpretation.

Competing interests Professor AJC is an advisor to Bayer, Boehringer-Ingelheim, Pfizer/BMS and Daiichi Sankyo, outside the submitted work. Professor GA has received research support from Menarini International; speaker bureau for Boehringer Ingelheim, Menarini International and Merck; consultant/advisory board for Menarini International, Merck and ACRAF. Dr SZG has received grants from BiO2 Medical, grants from Boehringer-Ingelheim, grants from Bristol Meyers Squibb, grants from BTG EKOS, grants from Daiichi Sankyo, grants from National Heart Lung and Blood Institute of the National Institutes of Health, grants from Janssen, grants from Thrombosis Research Group, personal fees from Bayer, personal fees from Boehringer-Ingelheim, personal fees from Bristol Meyers Squibb, personal fees from Daiichi Sankyo, personal fees from Janssen, personal fees from Portola, outside the submitted work. Professor SH reports personal fees from Aspen, personal fees from Bayer Healthcare, personal fees from BMS, personal fees from Daiichi-Sankyo, personal fees from Pfizer, personal fees from Sanofi outside the submitted work. Dr PJ has received consultant/ advisory board payments for Bayer Pharma AG, Boehringer Ingelheim and Novartis, outside of submitted work. Dr FM is an employee of Bayer Pharma AG. Dr SO has received consultant/advisory board payments for Bayer Pharma AG, Bristol-Myers Squibb Korea, Boehringer-Ingelheim Korea, Pfizer Korea, Sanofi-Aventis and St Jude Medical, outside the submitted work. Professor PR has received research support from St Jude Medical International and Biosense Webster, consultancy for Stereotaxis and Meda Pharmaceuticals, honoraria from Bayer, Cardiome, Pfizer, Bristol-Myers Squibb and Boehringer Ingelheim and ownership interest for Orion Pharma. Dr JS has received consultant and/or speaker fees from Amgen, Astra-Zeneca, Atricure, Boehringer-Ingelheim, Bristol-Myers Squibb, Cook Medical, Roche, Sanofi-Aventis, Sorin and Zoll (modest) and Bayer, Biosense Webster, Biotronik, Boston Scientific, Daiichi Sankyo, Medtronic, Novartis, Pfizer and St. Jude Medical (significant). He reports grant support through his institution from Bayer Healthcare, Biosense Webster, Biotronik, Boston Scientific, Daiichi Sankyo, Medtronic, und St. Jude Medical. He is codirector of CorXL. Dr MvE is an employee of Bayer HealthCare. Professor AKK is a principal investigator and received research Grants from Bayer AG; he received personal fee from Bayer AG; Boehringer-Ingelheim Pharma, Daiichi Sankyo Europe, Sanofi SA and Janssen Pharma. Drs GA, GK, WAM and AO have nothing to disclose.

\section{Patient consent Obtained.}

Ethics approval Independent ethics committee and hospital-based institutional review board approvals were obtained, as necessary, for the registry protocol.

Provenance and peer review Not commissioned; externally peer reviewed.

Data sharing statement No additional data are available.

Open Access This is an Open Access article distributed in accordance with the Creative Commons Attribution Non Commercial (CC BY-NC 4.0) license, which permits others to distribute, remix, adapt, build upon this work noncommercially, and license their derivative works on different terms, provided the original work is properly cited and the use is non-commercial. See: http:// creativecommons.org/licenses/by-nc/4.0/

\section{REFERENCES}

1. McKay J, Mensah GA. The Atlas of heart disease and stroke. US: World Health Organization \& Centers for Disease Control and Prevention, 2004. 
2. Kannel WB, Wolf PA, Benjamin EJ, et al. Prevalence, incidence, prognosis, and predisposing conditions for atrial fibrillation: population-based estimates. Am J Cardiol 1998;82(Suppl 1):2N-9N

3. Go AS, Hylek EM, Phillips KA, et al. Prevalence of diagnosed atrial fibrillation in adults: national implications for rhythm management and stroke prevention: the AnTicoagulation and Risk Factors in Atrial Fibrillation (ATRIA) Study. JAMA 2001;285:2370-5.

4. Camm AJ, Lip GY, De Caterina R, et al. Focused update of the ESC Guidelines for the management of atrial fibrillation: an update of the 2010 ESC Guidelines for the management of atrial fibrillation. Developed with the special contribution of the European Heart Rhythm Association. Eur Heart J 2012;33:2719-47.

5. Chugh SS, Havmoeller R, Narayanan K, et al. Worldwide epidemiology of atrial fibrillation: a Global Burden of Disease 2010 Study. Circulation 2014;129:837-47.

6. Benjamin EJ, Wolf PA, D'Agostino RB, et al. Impact of atrial fibrillation on the risk of death: the Framingham Heart Study. Circulation 1998;98:946-52.

7. Heeringa J, van der Kuip DA, Hofman A, et al. Prevalence, incidence and lifetime risk of atrial fibrillation: the Rotterdam study. Eur Heart J 2006;27:949-53.

8. Feinberg WM, Blackshear JL, Laupacis A, et al. Prevalence, age distribution, and gender of patients with atrial fibrillation. Analysis and implications. Archives of Internal Medicine 1995;155:469-73.

9. Poli D, Antonucci E. Epidemiology, diagnosis, and management of atrial fibrillation in women. Review. Int $J$ of Women's Health 2015;7:605-14.

10. Harvey RE, Coffman KE, Miller VM. Women-specific factors to consider in risk, diagnosis and treatment of cardiovascular disease. Womens Health (Lond) 2015;11:239-57.

11. Cove $\mathrm{CL}$, Albert $\mathrm{CM}$, Andreotti $\mathrm{F}$, et al. Female sex as an independent risk factor for stroke in atrial fibrillation: possible mechanisms. Thromb Haemost 2014;111:385-91.

12. Friberg J, Scharling $\mathrm{H}$, Gadsbøll $\mathrm{N}$, et al. Comparison of the impact of atrial fibrillation on the risk of stroke and cardiovascular death in women versus men (The Copenhagen City Heart Study). Am J Cardiol 2004:94:889-94.

13. Friberg L, Rosenqvist M, Lip GYH. Evaluation of risk stratification schemes for ischaemic stroke and bleeding in 182678 patients with atrial fibrillation: the Swedish Atrial Fibrillation cohort study. Eur Heart J 2012;33:1500-10.

14. Mikkelsen AP, Lindhardsen J, Lip GYH, et al. Female sex as a risk factor for stroke in atrial fibrillation: a nationwide cohort study. J Thromb Haemost 2012;10:1745-51.

15. Pancholy SB, Sharma PS, Pancholy DS, et al. Meta-analysis of gender differences in residual stroke risk and major bleeding in patients with nonvalvular atrial fibrillation treated with oral anticoagulants. Am J Cardiol 2014;113:485-90.

16. Volgman AS, Manankil MF, Mookherjee D, et al. Women with atrial fibrillation: greater risk, less attention. Gend Med 2009;6:419-32.

17. Avgil Tsadok M, Jackevicius CA, Rahme E, et al. Sex differences in stroke risk among older patients with recently diagnosed atrial fibrillation. Jama 2012;307:1952-8.

18. Gomberg-Maitland M, Wenger NK, Feyzi J, et al. Anticoagulation in women with non-valvular atrial fibrillation in the stroke prevention using an oral thrombin inhibitor (SPORTIF) trials. Eur Heart $J$ 2006;27:1947-53.

19. Marinigh $\mathrm{R}$, Lip GY, Fiotti N, et al. Age as a risk factor for stroke in atrial fibrillation patients: implications for thromboprophylaxis. J Am Coll Cardiol 2010;56:827-37

20. Camm AJ, Lip GY, De Caterina R, et al. 2012 focused update of the ESC Guidelines for the management of atrial fibrillation: an update of the 2010 ESC Guidelines for the management of atrial fibrillation.
Developed with the special contribution of the European Heart Rhythm Association. European Heart Journal 2012;33:2719-47.

21. January CT, Wann LS, Alpert JS, et al. 2014 AHA/ACC/HRS guideline for the management of patients with atrial fibrillation: a report of the American College of Cardiology/American Heart Association Task Force on practice guidelines and the Heart Rhythm Society. Circulation 2014;130:e199-267.

22. JCS Joint Working Group. Guidelines for pharmacotherapy of atrial fibrillation (JCS 2013). Circ J 2014;78:1997-2021.

23. Kirchhof P, Benussi S, Kotecha D, et al. 2016 ESC Guidelines for the management of atrial fibrillation developed in collaboration with EACTS: the task force for the management of atrial fibrillation of the European Society of Cardiology (ESC) developed with the special contribution of the European Heart Rhythm Association (EHRA) of the ESC endorsed by the European Stroke Organisation (ESO). European Heart Journal 2016;37:2893.

24. Kakkar AK, Mueller I, Bassand JP, et al. International longitudinal registry of patients with atrial fibrillation at risk of stroke: global anticoagulant registry in the FIELD (GARFIELD). Am Heart $J$ 2012;163:13-19.

25. Lip GY, Rushton-Smith SK, Goldhaber SZ, et al. Does sex affect anticoagulant use for stroke prevention in nonvalvular atrial fibrillation? The prospective global anticoagulant registry in the FIELD-atrial fibrillation. Circ Cardiovasc Qual Outcomes 2015;8 (Suppl 1):S12-20.

26. Emdin CA, Wong CX, Hsiao AJ, et al. Atrial fibrillation as risk factor for cardiovascular disease and death in women compared with men: systematic review and meta-analysis of cohort studies. BMJ 2016;532:h7013.

27. Wagstaff AJ, Overvad TF, Lip GY, et al. Is female sex a risk factor for stroke and thromboembolism in patients with atrial fibrillation? A systematic review and meta-analysis. QJM: Monthly Journal of the Association of Physicians 2014;107:955-67.

28. Bosch RF, Pittrow D, Beltzer A, et al. Gender differences in patients with atrial fibrillation. Herzschr Elektrophys 2013;24:176-83.

29. Rienstra M, Van Veldhuisen DJ, Hagens VE, et al. Gender-related differences in rhythm control treatment in persistent atrial fibrillation: data of the Rate Control Versus Electrical Cardioversion (RACE) study. J Am Coll Cardiol 2005;46:1298-306.

30. Dagres N, Nieuwlaat R, Vardas PE, et al. Gender-related differences in presentation, treatment, and outcome of patients with atrial fibrillation in Europe: a report from the Euro Heart Survey on Atrial Fibrillation. J Am Coll Cardiol 2007;49:572-7.

31. Olesen JB, Fauchier L, Lane DA, et al. Risk factors for stroke and thromboembolism in relation to age among patients with atrial fibrillation: the Loire Valley atrial fibrillation project. Chest 2012;141:147-53.

32. Franklin SS, Gustin W IV, Wong ND, et al. Hemodynamic patterns of age-related changes in blood pressure. The Framingham Hear Study. Circulation 1997;96:308-15.

33. Lip GY, Clementy N, Pericart L, et al. Stroke and major bleeding risk in elderly patients aged $>/=75$ years with atrial fibrillation: the Loire Valley atrial fibrillation project. Stroke 2015;46:143-50.

34. van Walraven C, Hart RG, Connolly S, et al. Effect of age on stroke prevention therapy in patients with atrial fibrillation: the atrial fibrillation investigators. Stroke 2009;40:1410-16.

35. Garcia D, Regan S, Crowther M, et al. Warfarin maintenance dosing patterns in clinical practice: implications for safer anticoagulation in the elderly population. Chest 2005;127:2049-56.

36. Sullivan RM, Zhang J, Zamba G, et al. Relation of gender-specific risk of ischemic stroke in patients with atrial fibrillation to differences in warfarin anticoagulation control (from AFFIRM). Am J Cardiol 2012;110:1799-802. 